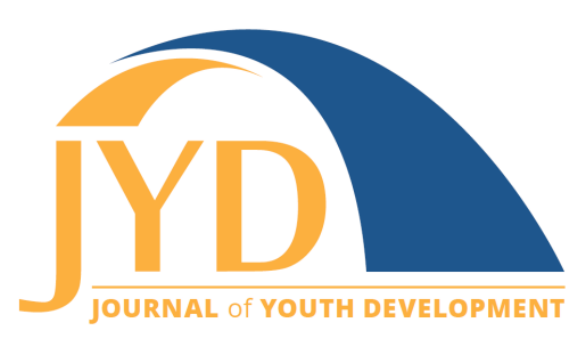

http://jyd.pitt.edu/ | Vol. 15 Issue 4 DOI 10.5195/jyd.2020.876 | ISSN 2325-4017 (online)

\title{
Identification of Priority Skill Areas for Volunteer Professional Development
}

\author{
Car Mun Kok \\ University of California, Agriculture and Natural Resources \\ cmkok@ucanr.edu
}

Dorina M. Espinoza

University of California, Agriculture and Natural Resources

dmespinoza@ucanr.edu

Steven M. Worker

University of California, Agriculture and Natural Resources

smworker@ucanr.edu

\section{Charles Go}

University of California, Agriculture and Natural Resources

cggo@ucanr.edu

JoLynn C. Miller

University of California, Agriculture and Natural Resources

jlmiller@ucanr.edu

\section{Abstract}

Youth development programs often rely on volunteers to deliver programming to young people. Our study explored the skills and competencies volunteers self-identified as important for their roles. We analyzed qualitative responses to 2 open-ended questions asking University of California 4- $H$ volunteers to identify priority skills to aid in their volunteer development. Using inductive thematic analysis, we developed a coding scheme to analyze 1,144 responses. Participants reported the need for professional development in content-specific areas, program management basics, and child development. Volunteers also reported desiring training in educational practices, organizational skills, specific volunteer roles, and communication skills. The modalities through which volunteers were willing to develop these skills were peer-to-peer learning; online, in-person, classes and conferences; and continuous education. Given the importance of adult volunteers to youth development programs, it is essential that volunteers' professional and skill development be supported by both effective and preferred approaches.

Key words: volunteer skill development, volunteer professional development 


\section{Introduction}

Adults play a crucial role in youth development (Li \& Julian, 2012). The connections that youth form with adults contribute to developmental relationships, shown to have a positive impact on youth development (Stukas et al., 2006). Youth development programs (YDPs) offering structured and formal activities that connect youth with adult volunteers may provide a safe place for youth to benefit from sustained relationships with caring adults (Lerner et al., 2005). Professionals managing YDPs provide formal trainings to volunteers to enhance their skills and ensure the safety of youth and adults. YDPs may also encourage adult engagement with youth by providing formalized volunteer roles where adults have direct program delivery responsibilities with youth. This provides an opportunity for adults who have no prior or prescribed involvement with youth (unlike a parent or youth worker) to be positive role models for youth (Stukas et al., 2006).

Adult volunteers are an essential component of the Cooperative Extension system, especially for the 4-H YDP. In 2018, more than 369,000 4-H adult volunteers served nearly six million young people across the United States (U.S. Department of Agriculture [USDA], 2018). The 4-H Youth Development Program is administered by Cooperative Extension-a partnership among the USDA, 100 public Land Grant universities, and local governments (USDA, 2016). Adult volunteers with roles involving direct delivery help to improve the psychological and/or physical health and welfare of youth through their service (Stukas et al., 2006). Volunteers serve as positive role models and mentors to contribute to positive youth development. Coupled with youth engagement and other program components, adult volunteers help increase positive youth development outcomes, otherwise known as the six Cs: confidence, competence, character, caring, connection, and contribution. (Lerner et al., 2005; Arnold et al., 2009).

Given the importance of 4-H volunteers in youth development and the desire to increase the reach of YDPs, Extension professionals must be prepared to deliver effective professional development that equips volunteers with the skills to meet the needs of the program and clientele. Our study builds on the existing research on volunteer competencies and effective delivery modalities. 


\section{Volunteering and Volunteer Engagement}

Previous empirical work has examined factors of volunteer engagement, benefits of volunteering, and motivations for volunteering. Specific to $4-\mathrm{H}$ volunteers, D. J. White and Arnold (2003) found that volunteers (a) wanted to make a difference in the lives of youth, (b) received satisfaction through helping others, (c) often had children who are involved in the 4-H program, (d) enjoyed volunteer work, (e) increased their skills in youth development, and (f) increased their knowledge in a specific area or topic. Increasing their skillset and knowledge in certain topic areas was a reason volunteers reported for volunteering (D. J. White \& Arnold, 2003). Additionally, volunteers with greater skills and knowledge also tend to have higher competency levels, which increases their confidence and ability to be successful volunteers (Culp, McKee, \& Nestor, 2007). Community service self-efficacy or "volunteers' confidence in their ability to make a difference in their communities through service activities" was found to be positively related to volunteer engagement (Harp et al., 2017, p. 445).

Braker and colleagues (2000) categorized the benefits of volunteering in 4-H into personal growth, community involvement, and economic benefits. Personal growth benefits included helping others, making new friends, and gaining knowledge and skills. Community involvement benefits included volunteers gaining a better understanding of their community and use of community facilities and services. Volunteers reported work efficiency and networking potential as economic benefits. It is important to acknowledge that volunteers reported gaining knowledge, skills, and self-confidence as personal growth benefits to and reasons for volunteering. Similarly, Culp et al. (2007) found that increased skills and knowledge in volunteers are associated with greater confidence to be competent volunteers, which in turn increases their engagement. Therefore, it is important to understand more about the knowledge and skills that volunteers want to gain from their volunteering experiences, and the professional development opportunities they want in order to build those skills

\section{Volunteer Knowledge, Skills, and Competencies}

The National Research Council and Institute of Medicine (2002) released a seminal report wherein they outlined seven program features associated with youth development outcomes: support for efficacy and mattering, physical and psychological safety, opportunities for skill building, appropriate structure, positive social norms, opportunities to belong, and supportive relationships. These program elements are influenced by adults, and thus reflect the skill and knowledge areas needed for volunteers to be successful in their service. 


\section{Skill Areas for Volunteer Professional Development}

In the intervening years since the report, the literature on the knowledge, skills, and competencies needed by adults has grown. A broad base of literature in Cooperative Extension has explored these focus areas needed by 4-H volunteers (e.g., Barker \& O'Brien, 2001; Culp et al., 2007; Radhakrishna \& Ewing, 2011; Singletary et al., 2006). Barker and O'Brien (2001) advanced a Kansas volunteer competency framework in which Extension staff ranked competencies. The ranked domains included professionalism, working with youth and adults, knowledge of program, planning, and organizing programs. Singletary et al. (2006) surveyed Nevada 4-H volunteers to prioritize adult skills thought to impact youth outcomes; the highest ranked skills included making sure the facility is safe, listening to youth, ensuring youth act appropriately, and helping youth feel important to the program.

In 2006, the Volunteer Research Knowledge and Competency Taxonomy (VRKC) was developed by Culp et al. (2006) to identify the competencies 4-H volunteers need to implement youth development programs. The VRKC includes communications, organization, program management, educational design and delivery, positive youth development, and interpersonal characteristics. In order to be effective, volunteers should be able to communicate well verbally and non-verbally, plan and deliver programming with others, understand and follow 4-H program policies, use evidence-based information to promote positive youth development, and develop effective working relationships with others.

\section{Volunteer Professional Development}

Research on volunteer professional development has suggested the importance of ongoing and learner-centered professional development on volunteers' abilities to enhance young people's learning experiences (Hunzicker, 2011; Smith, 2013). However, most professional development offered for 4-H volunteers utilizes didactic teaching strategies. Workshops are a common mode of skill information delivery but are characterized by a top-down approach with skilled professionals demonstrating knowledge to participants (Jorgenson \& Vanosdall, 2002; Kaslon et al., 2005; Senyurekli et al., 2006; Smith et al., 2017). These strategies are less effective than reform-based approaches, which are continuous, are learner-centered, promote active learning, and connect to the broader organizational system (Hunzicker, 2011; Smith \& Schmitt-McQuitty, 2013). Professional development for 4-H volunteers are also often intermittent and mostly offered in response to a specific situation (Smith et al., 2017).

Volunteers utilize a combination of in-person and online methods for receiving and engaging in professional development opportunities (Smith et al., 2017). Common topics for professional 
development of 4-H volunteers include leadership, educational/topic-specific, family community leadership, leader and officer/role-specific training, monthly training, working with youth, and county-level training on program policies and organizational structure (Hoover \& Connor, 2001; VanWinkle et al., 2002). When delivered effectively through learner-centered and reform-based approaches, trainings have been shown to increase volunteers' knowledge about (a) 4-H and its organizational structure, (b) roles and leadership responsibilities, (c) teaching techniques and pedagogy for youth in various age groups, and (d) planning and organization of meetings and other activities (Smith \& Schmitt-McQuitty, 2013; VanWinkle et al., 2002). It was also reported that by attending the trainings and serving as 4-H leaders, volunteers gained teaching, organizational, and leadership skills, and they applied these skills to other areas of their life, such as work and family (VanWinkle et al., 2002).

\section{The Present Study}

In summary, volunteers reported that increasing skills and knowledge is a motivation for and a benefit from volunteering. Additionally, continuous and learner-centered professional development improves the skills and knowledge of volunteers. Strengthening skills and knowledge improves volunteer engagement. Therefore, it is important for Extension professionals to better understand the skill areas and methods of volunteer professional development needed for their roles. Addressing these issues, our study explored the skill areas and competencies that 4- $\mathrm{H}$ volunteers identified as important and the professional development modalities through which they want to build skills and competencies.

\section{Methodology}

This paper is part of a larger study aimed to understand the experiences and attitudes of $4-\mathrm{H}$ adult volunteers in the University of California (UC) 4-H YDP. The larger investigation utilized a 24-item survey informed by a previous study assessing 4-H volunteer competencies, experiences, and attitudes (Junge et al., 1999). Our adapted survey asked respondents to report their volunteer involvement (number of years volunteering and roles), training they received (including in-person and online), their experience volunteering (perceived changes in the organization, its leadership), and demographic information (including age, gender, race, and level of education completed). The UC Davis Institutional Review Board approved all forms and procedures for this study. 
The survey was sent electronically using Qualtrics to 4-H adult volunteers during the end of the 2016 program year. We received responses from 2,107 volunteers; the entire volunteer corps was invited to participate (total 9,714; $22 \%$ response rate; note that many adults shared the same email address so only 7,953 email invitations were sent). Participant demographics are summarized in Table 1.

Table 1. Demographic Information of California 4-H Adult Volunteers

\begin{tabular}{|c|c|c|}
\hline Demographic & $\begin{array}{c}\text { Sample } \\
\text { percentage (\%) } \\
(n=2,107)\end{array}$ & $\begin{array}{c}\text { Population } \\
\text { percentage (\%) } \\
(\boldsymbol{N}=\mathbf{9}, \mathbf{7 1 4})\end{array}$ \\
\hline \multicolumn{3}{|l|}{ Gender } \\
\hline Female & 84 & 73 \\
\hline Male & 16 & 27 \\
\hline \multicolumn{3}{|l|}{ Ethnicity } \\
\hline Non-Hispanic or Latino & 93 & 91 \\
\hline Hispanic or Latino & 7 & 9 \\
\hline \multicolumn{3}{|l|}{ Race } \\
\hline White & 85 & 87 \\
\hline Black or African American & 1 & 1 \\
\hline Asian & 3 & 2 \\
\hline American Indian or Alaska Native & 4 & 3 \\
\hline Native Hawaiian or other Pacific Islander & 1 & 0 \\
\hline Other/Undetermined & 6 & 6 \\
\hline \multicolumn{3}{|l|}{ Education level } \\
\hline High school/GED & 4 & 8 \\
\hline Some college & 21 & 30 \\
\hline 2-year college degree & 19 & 13 \\
\hline 4-year college degree & 36 & 32 \\
\hline Graduate degree & 20 & 17 \\
\hline
\end{tabular}


Table 1. (continued)

\begin{tabular}{|l|c|c|}
\hline Demographic & $\begin{array}{c}\text { Sample } \\
\text { percentage (\%) } \\
(\boldsymbol{n}=\mathbf{2 , 1 0 7 )}\end{array}$ & $\begin{array}{c}\text { Population } \\
\text { percentage (\%) } \\
(\mathbf{N}=\mathbf{9}, \mathbf{7 1 4})\end{array}$ \\
\hline 4-H roles served & & \\
\hline Project leader & 94 & \\
\hline Club administrative leader & 42 & \\
\hline Club or county committee & 49 & \\
\hline Camp chaperone & 30 & \\
\hline Youth leadership team advisor & 21 & \\
\hline Resource key leader & 20 & \\
\hline County council or management board & 26 & \\
\hline Sectional or regional council & 12 & $45.4(11.7)$ \\
\hline After-school or mentoring leader & 9 & 45 \\
\hline Other & 12 & $7.4(21.8)$ \\
\hline Mean age in years (SD) & $48.2(11.3)$ & 5 \\
\hline Median age in years & 48 & \\
\hline Mean years as a 4-H volunteer $(S D)$ & $8.7(8.8)$ & \\
\hline Median years as a 4-H volunteer & 6 & \\
\hline & & \\
\hline
\end{tabular}

For this paper, we focused on volunteer development needs as identified by 4-H volunteers. Specifically, we asked adult volunteers two open-ended questions:

1. Thinking of your local 4-H programs and activities, what skill areas do you feel should be priorities for volunteer development training?

2. For you personally, what professional development opportunities would help you be a better volunteer?

We analyzed 1,144 and 1,008 responses respectively to the two qualitative questions. We applied iterative inductive thematic analysis (Braun \& Clarke, 2006) without a pre-existing coding scheme to each question independently (e.g., A. J. White \& Scanga, 2019). Separate codes were applied for each distinct idea or concept contained in the response. The first three authors independently reviewed the first 100 responses of each of the two separate questions. Comparison of initial codes was made to ensure codes were anchored to the data (Corbin \& Strauss, 2015), independent, and defined and created in agreement. When disagreements arose, we discussed until reaching consensus. We repeated this process with a sub-sample of 600 responses. During comparison and discussion of the codes applied to each of the two 
separate questions, a decision was made to consolidate the coding given the similarity of the two open-ended questions and responses. The final step was to code the remaining responses. Each coder also coded approximately $10 \%$ of another's block. We discussed disagreements and conflict, and then revised code definitions. The coding scheme was modified with codes added or merged and resulted in seven codes identifying skill areas for volunteer professional development and five codes identifying preferred approaches to volunteer professional development.

\section{Findings}

Participant responses reflected the skill areas and professional development modalities they identified as important while serving in their volunteer roles with the UC 4-H YDP. The average response word count was 13; median word count was 11 . Forty three percent of responses were marked with one code, $30 \%$ with two codes, and $27 \%$ with three or more codes.

\section{Skill Areas for Volunteer Professional Development}

We identified seven skill areas volunteers reported as important for their professional development: curricula and project-specific subject matter, program management basics, child development, educational practices, organizational skills, specific volunteer roles, and communication skills (see Table 2). The three most prevalent were curricula and project-specific subject matter, program management basics, and child development.

\section{Table 2. Volunteers' Priority Skill Areas}

\begin{tabular}{|l|c|}
\hline Theme & $\begin{array}{c}\text { Percentage of participants with } \\
\text { a response containing the code } \\
\text { (\%) }\end{array}$ \\
\hline Curricula and Project-specific Subject Matter & 17.8 \\
\hline Program Management Basics (procedures, policy, record books) & 11.7 \\
\hline Child Development ("age and stages") & 11.1 \\
\hline $\begin{array}{l}\text { Educational Practices (pedagogy, lesson planning, teaching, experiential } \\
\text { learning, service learning) }\end{array}$ & 9.6 \\
\hline Organizational Skills (coordination skills, time management) & \\
\hline Communication Skills (public speaking) & 7.9 \\
\hline Role-specific & 7.4 \\
\hline
\end{tabular}




\section{Curricula and Project-Specific Subject Matter}

Volunteers reported that training on project subject matter and resources on topic or projectspecific curriculum and activities were essential for their volunteer roles. Volunteers also reported they wanted training specific to curriculum use, especially in animal-related projects: "For instance, in poultry, what is the curriculum 4-H wants taught for each age group? We can teach what we know but what we teach must be right and correct" (Female, age 42, 2 years of volunteer service).

\section{Program Management Basics}

Volunteers also reported they needed skills for program management basics including 4-H organizational policies and procedures. For example, one volunteer described wanting a training on "the policies and management side of running a club" (Female, 30, 1 year). Another volunteer said he wanted to have "a good background on 4-H and its policies and its structure" (Male, 58, 8 years).

\section{Child Development}

Volunteers also reported it was important to develop skills in child development, such as engaging children in different developmental stages, good practices in working with youth, and helping children feel safe. One respondent identified "child development and tips for engaging children" (Female, 31, 1 year) as important while another indicated "how to work with different ages and stages" (Female, 32, 11 years).

\section{Other Skill Areas}

Volunteers reported additional skill areas, although they were less prevalent in the data than the top three. These skill areas included educational practices, organizational skills, specific volunteer roles, and communication skill. Educational practices included experiential learning, pedagogical knowledge, "guidance on good teaching practices" (Female, 63, 21 years), lesson planning, and service learning. Organizational skills encompassed planning, scheduling, and time management as "organization, planning ahead, and communication are vital to ensuring the success of a project or event" (Female, 22, 3 years). For role-specific training, volunteers wanted training to develop skills relevant to a specific role (e.g., project leader, club leader). 
[I want] a guideline of responsibilities for the role I have volunteered for. Examples of what needs to be taught/offered for my role. . . What are our responsibilities when it comes to the parents in the group . . . or even leader boundaries? (Female, 42, 2 years)

Communication skills included public speaking, conflict management, and cultural competency. Finally, volunteers reported a host of other skill areas, but they were not prevalent or consistent across the data set. These skill areas included adult volunteer recruitment (5\%), leadership (3\%), youth-adult partnerships (3\%), outreach and marketing (2\%), teamwork (1\%), fundraising (1\%), physical safety (first aid) (1\%), and emotional safety (1\%).

\section{Preferred Modalities to Volunteer Professional Development}

Although not asked explicitly, $21 \%$ of respondents reported on professional development modalities (i.e., types, methods, and approaches of volunteer professional development) they preferred. There was such a prevalence of response to preferred approaches that we were able to identify five preferred approaches to volunteer professional development: peer-to-peer learning, online, in-person, classes and conferences, and continuous education (See Table 3).

Table 3. Volunteers' Preferred Approach for Skill Learning and Professional Development

\begin{tabular}{|l|c|}
\hline Theme & $\begin{array}{c}\text { Percentage of participants } \\
\text { with a response containing } \\
\text { the code (\%) }\end{array}$ \\
\hline Peer-to-peer learning & 42.1 \\
\hline Online & 17.8 \\
\hline Classes and conferences & 9.5 \\
\hline Continuous education & 8.0 \\
\hline In-person & 7.6 \\
\hline
\end{tabular}

The top approach volunteers shared was their preference for peer-to-peer learning, which included activities such as mentoring, coaching, working in teams, and networking. Participants reported wanting interactions with other volunteers who were participating in similar projects, events, and activities, not just participating in expert-led workshops. One volunteer expressed her preference as "meeting other project leaders doing the same project-bouncing ideas off 
each other" (Female, 45, 10 years). Another volunteer mentioned how peer-to-peer learning would be helpful to new and returning volunteers:

It would be great [to have examples] of what specific project leaders from other counties have found to be successful techniques to teaching and leading their particular projects ... how they plan meetings, what activities they do, and how often and for how long they meet. This would be helpful to new volunteers as they are learning how to structure projects and current volunteers as they gain inspiration from others across the state. (Female, 22, 3 years).

Volunteers also reported wanting to participate in trainings that were online, in-person, classes and conferences, and continuous education. Volunteers who wanted online training stated that it was helpful in an area that is "rural with a dwindling target population" (Female, 56, 25 years). On the other hand, volunteers who wanted in-person training preferred "more face-toface communication and workshop experience" (Female, 71, 40 years). Coupled with a preference for face-to-face training, one volunteer mentioned having classes on recruiting volunteers and sharing resources:

4-H needs an adult volunteer class... [how to] recruit adults and give them the tools for projects and ask each adult what they can give back to the club and then get them the resources on being a project leader. (Female, 44, 1 year)

Other volunteers wanted training in the form of "volunteer continuing education in leading and teaching youth several times a year" (Female, 52, 3 years) instead of just once a year so that there is continued learning and growth in $4-\mathrm{H}$ volunteers.

Regardless of the specific modality, volunteers noted a need to have information that was simple and easy to find (7\%) plus communicated in a timely manner (7\%). As one volunteer mentioned, "the website needs to be easy to navigate. Training materials should be updated, free, and easily downloadable" (Male, 47, 4 years).

\section{Discussion}

Our study identified skill areas and competencies that 4-H volunteers reported as important to their roles in addition to professional development modalities through which they want to build those skills and competencies. Interestingly, the skills areas (curricula and project-specific subject matter, program management basics, child development, educational practices, 


\section{Skill Areas for Volunteer Professional Development}

organization/planning, and communication) reported in our study are associated with the core competencies for 4-H volunteers. This is not surprising as we identified similar findings to Culp and colleagues' (2007) study through qualitative analysis of open-ended prompts asking 4-H volunteers to identify the skills they need. However, differences between their findings and ours were present. Our six most prevalent themes were found in the earlier study, although the rankings differed. Curricula and project-specific subject matter emerged first in our study but third in Culp et al.; program management basics were second in our study but eleventh in the previous. Interestingly, technology and computer skills emerged as seventh in Culp et al., but reported by only $0.4 \%$ of the respondents in our study; perhaps in the intervening decade, computer skills have become more common and as such, are no longer a need for specific skill development. Additionally, the personal traits of interpersonal skills and patience emerged in Culp et al. but did not appear in our study. Role-specific skills occurred in our study but not in the previous. Despite these differences, the core competencies vital for 4-H volunteers were also the skill areas volunteers reported should be priorities for volunteer professional development to help them be better volunteers. Therefore, in order to develop and grow a successful 4-H YDP, professional development opportunities are needed in these skill areas.

It is also important to acknowledge that volunteers might not recognize what types of professional development opportunities might be most beneficial in their volunteer role. Therefore, these opportunities need to be offered in a manner that helps volunteers form new ideas for their roles. Professional development opportunities could be mandated and/or made into a series of continuing education and professional development sessions that build upon each other. Professional development sessions might also focus on multiple skills that are highly correlated (e.g., organization/planning and communication) so volunteers are exposed to more than one skill development in a session.

Moreover, participants in the present study shared their preferred professional development approach as ongoing, learner-centered, and group-based, including peer-to-peer (e.g., mentoring, coaching, teamwork, and networking). Volunteers wanted continuous education and expressed preferences for both online and in-person methods of receiving training. These reform-based approaches of volunteer professional development have been shown to be more effective at improving practice than one-time, expert-led workshops (Schmitt-McQuitty et al., 2019; Smith \& Schmitt-McQuitty, 2013). Yet, the prevailing approach to 4-H volunteer professional development is single episode, expert-led workshops and conferences (Kalson et al., 2005; Senyurekli et al., 2006; Smith et al., 2004; Smith et al., 2017). We recommend 
additional research exploring why there is continued use of ineffective and non-preferred traditional professional development for 4-H volunteers.

Furthermore, it is important for Extension professionals to account for accessibility to resources, especially in remote areas where transportation or internet connectivity may be an issue. It is best practice to have professional development opportunities in a variety of delivery modes, whenever possible, to be able to reach diverse volunteers. Further, modes of continued professional development, such as engaging in communities of practice, have been shown to be effective for 4-H volunteers in supporting youth development (Smith \& Schmitt-McQuitty, 2013). An area which may warrant additional research is how Extension and statewide programs may better support county-based 4-H staff to tailor trainings to serve the 4-H volunteers in their communities.

While the findings from this study have yet to be fully implemented at the UC 4-H statewide program level, recommendations have been made for more professional development practices that utilize a peer-to-peer and networking approach that is continuous and learner-centered. The findings could also be presented during monthly virtual 4-H statewide meetings to help inform 4-H volunteer professional development practices. Findings have also been used in individual counties by local staff to inform volunteer training and development. A comprehensive internal report of the findings from this study was also developed to help inform the UC 4-H statewide efforts on volunteer professional development and other needs.

\section{Limitations and Future Directions}

Research on volunteerism, especially in youth organizations, focuses on the antecedents of volunteering, the current professional development resources for volunteers, and the skillset of competent volunteers. This study provided a better understanding of what volunteers say should be priorities for skill building and how they want to learn.

Our study utilized a qualitative research methodology to analyze and interpret the data. The findings were based on participants' responses to open-ended questions without being limited to pre-determined categories that could shape their responses. The utilization of a mixed methods approach could garner more in-depth understanding on the participants' experiences. Future analysis of the qualitative and quantitative data from this survey could produce more robust findings to further inform volunteer development. Our study also utilized a self-report survey as the instrument for data collection, which could present issues with response and 
selection bias as well as with participant honesty. Future studies utilizing other research methods for data collection and analysis could provide further insight into 4-H and other youth organizations' volunteer experiences.

The data from this study is specific to the UC 4-H YDP. Caution must be taken in generalizing findings to other youth organizations and Extension programs in other states. Other youth organizations and Extension programs may use a different framework for youth development, have a different program delivery mode that engages volunteers in different roles, or have a different mission and vision for serving youth. Further studies on other youth-serving programs could provide information on how various youth-serving programs compare to one another in terms of volunteerism and professional development.

\section{Conclusion}

Volunteers are key to youths' growth and development. Volunteers facilitate young people's development of the six Cs of positive youth development through their interaction, engagement, and connection with 4-H youth. These volunteers serve as positive role models, mentors, and advisers for youth. They lead and support activities that promote the development of the six Cs, which steer youth to be good community stewards and successful individuals (Benson et al., 2006; Lerner et al., 2005).

Given the importance of adult volunteers to the 4-H program and to the positive development of youth, it is essential that 4-H, other Extension professionals, and other youth-serving organizations support volunteers' education and skill development process. Youth educators who are highly skilled, whether volunteer or paid staff, provide more positive and effective contribution to develop successful youth (Borden et al., 2011; Pozzoboni, \& Kirshner, 2016). Youth who are successful (e.g., who have high development on the six Cs) are more likely be contributing members that positively impact their communities and society (Lerner et al., 2005).

\section{Acknowledgements}

We acknowledge the University of California, Agriculture and Natural Resources Developing Volunteer Capacities workgroup and Gemma Miner for coordinating the larger study from which the data in our paper was drawn. 
Journal of Youth Development | http://jyd.pitt.edu/ | Vol. 15 Issue 4 DOI 10.5195/jyd.2020.876

Skill Areas for Volunteer Professional Development

\section{References}

Arnold, M. E., Dolene, B. J., \& Rennekamp, R. A. (2009). An assessment of 4-H volunteer experience: Implications for building positive youth development capacity. Journal of Extension, 475). https://joe.org/joe/2009october/a7.php

Barker, W. A., \& O'Brien, D. (2001). Project leaders' and volunteers' competencies of Kansas top eight 4-H programs. Journal of Extension, 3966). https://www.joe.org/joe/2001december/rb6.php

Benson, P. L., Scales, P. C., Hamilton, S. F., \& Sesma, A., Jr. (2006). Positive youth development: Theory, research, and applications. In R. M. Lerner \& W. Damon (Eds.), Handbook of child psychology: Theoretical models of human development (pp. 894-941). John Wiley \& Sons.

Borden, L. M., Schlomer, G. L., \& Wiggs, C. B. (2011). The evolving role of youth workers. Journal of Youth Development, 6(3), 126-138. https://doi.org/10.5195/jyd.2011.179

Braker, M. J., Leno, J. R., Pratt, C. C., \& Grobe, D. (2000). Oregon extension volunteers: Partners in action. Journal of Extension, 38(2). https://www.joe.org/joe/2000april/rb3.php

Braun, V. \& Clarke, V. (2006). Using thematic analysis in psychology. Qualitative Research in Psychology, 3, 77-101.

Corbin, J., \& Strauss, A. L. (2015). Basics of qualitative research: Techniques and procedures for developing grounded theory ( $4^{\text {th }}$ ed.). SAGE

Culp, K., McKee, R. K., \& Nestor, P. (2006). Volunteer research and knowledge competency: Taxonomy for 4-H youth development. National 4-H Headquarters. https://4-h.org/wpcontent/uploads/2016/02/VRKC.pdf

Culp, K., McKee, R. K., Nestor, P. (2007). Identifying volunteer core competencies: Regional differences. Journal of Extension, 45(6). https://joe.org/joe/2007december/a3.php

Harp, E. R., Scherer, L. L., \& Allen, J. A. (2017). Volunteer engagement and retention: Their relationship to community service self-efficacy. Nonprofit and Voluntary Sector Quarterly, 46(2), 442-458. https://doi.org/10.1177/0899764016651335

Hoover, T., \& Connor, N. J. (2001). Preferred learning styles of Florida association for family and community education volunteers: Implications for professional development. Journal of Extension, 39(3), 1-8. https://www.joe.org/joe/2001june/a3.php

Hunzicker, J. (2011). Effective professional development for teachers: A checklist. Professional Development in Education, 372), 177-179. https://doi.org/10.1080/19415257.2010.523955

Jorgenson, O., \& Vanosdall, R. (2002). The death of science? What we risk in our rush toward standardized testing and the three R's. Phi Delta Kappan, 83(8), 601-605. https://doi.org/10.1177/003172170208300808 
Junge, S., George, J., Humphrey, S., McAllister, T., DeLasaux, M., Conklin-Ginop, E. (1999). Measuring the effectiveness of University of California Cooperative Extension's North Region 4-H club program: A survey of 4-H volunteer leaders. University of California Cooperative Extension.

Kaslon, L., Lodl, K., \& Greve, V. (2005). Online leader training for 4-H volunteers: A case study of action research. Journal of Extension, 43(2). https://www.joe.org/joe/2005april/a4.php

Lerner, R. M., Lerner, J. V., Almerigi, J., Theokas, C., Phelps, E., Gestsdottir, S., Naudeau, S., Jelicic, H., Alberts, A. E., Ma, L., Smith, L. M., Bobek, D. L., Richman-Raphael, D., Simpson, I., Christiansen, E. D., \& von Eye, A. (2005). Positive youth development, participation in community youth development programs, and community contributions of fifth grade adolescents: Findings from the first wave of the 4-H Study of Positive Youth Development. Journal of Early Adolescence, 25(1), 17-71. https://doi.org/10.1177/0272431604272461

Li, J., \& Julian, M. M. (2012). Developmental relationships as the active ingredient: A unifying working hypothesis of "what works" across intervention settings. American Journal of Orthopsychiatry, 82(2), 157-166. https://doi.org/10.1111/j.1939-0025.2012.01151.x

National Research Council and Institute of Medicine (2002). Community programs to promote youth development. National Academy Press.

Pozzoboni, K. M., \& Kirshner, B. (Eds.) (2016). The changing landscape of youth work: Theory and practice for an evolving field. Information Age.

Radhakrishna, R., \& Ewing, J. C. (2011). Relationships between 4-H volunteer leader competencies and skills youth learn in 4-H programs. Journal of Extension, 49(4), 1-9. https://www.joe.org/joe/2011august/rb2.php

Schmitt-McQuitty, L., Worker, S. M., \& Smith, M. H. (2019). Lesson study model of 4-H professional development: Data-driven improvements to educator practice. Journal of Youth Development, 14(1), 131-154. https://doi.org/10.5195/jyd.2019.693

Senyurekli, A., Dworkin, J., \& Dickinson, J. (2006). On-line professional development for Extension educators. Journal of Extension, 44(3). https://joe.org/joe/2006june/rb1.php

Singletary, L., Smith, M., \& Evans, W. P. (2006). Self-perceived 4-H leader competencies and their relation to the skills youth learn through $4-\mathrm{H}$ youth development programs. Journal of Extension, 44(4). https://joe.org/joe/2006august/rb2.php

Smith, M. (2013). Findings show lesson study can be an effective model for professional development of 4-H volunteers. California Agriculture, 6ス 1), 54-61. https://doi.org/10.3733/ca.v067n01p54

Smith, M., Meehan, C. L., Enfield, R., George, J. L., Young, J. C. (2004). Improving county-based science programs: Bringing out the science teacher in your volunteer leaders. Journal of Extension, 42(6). https://www.joe.org/joe/2004december/a5.php 
Journal of Youth Development | http://jyd.pitt.edu/ | Vol. 15 Issue 4 DOI 10.5195/jyd.2020.876 Skill Areas for Volunteer Professional Development

Smith, M. H., \& Schmitt-McQuitty, L. (2013). More effective professional development can help 4-H volunteers address need for youth scientific literacy. California Agriculture, 671), 47-53. https://doi.org/10.3733/ca.v067n01p47

Smith, M., Worker, S. M., Schmitt-McQuitty, L., Meehan, C. L., Lewis, K. M., Schoenfelder, E., \& Brian, K. (2017). Prevalent approaches to professional development in state 4-H programs. Journal of Extension, 55(4). https://joe.org/joe/2017august/rb2.php

Stukas, A. A., Daly, M., \& Clary, E .G. (2006). Lessons from research on volunteering for mobilizing adults to volunteer for positive youth development. In E. G. Clary \& J. E. Rhodes (Eds.), Mobilizing adults for positive youth development: Strategies for closing the gap between beliefs and behaviors (pp. 65-82). Springer. https://doi.org/10.1007/0-387-29340-X 4

U.S. Department of Agriculture. (2016). 4-H implementation: The working relationship. (Fact Sheet). National Institute of Food and Agriculture. https://nifa.usda.gov/sites/default/files/resource/4H\%20Implementation.pdf

U.S. Department of Agriculture. (2018). 4-H reports: National 4-H enrollment. Research, Education, \& Economics Information System. https://reeis.usda.gov/reports-and-documents/4-h-reports

VanWinkle, R., Busler, S., Bowman, S. R., \& Mannogian, M. (2002). Adult volunteer development: Addressing the effectiveness of training new 4-H leaders. Journal of Extension, 40(6). https://www.joe.org/joe/2002december/a4.php

White, A. J., \& Scanga, L. H. (2019). Volunteer research and knowledge competency codebook: A tool for identifying volunteer needs. Journal of Extension, 5Х1). https://www.joe.org/joe/2019february/tt3.php

White, D. J., \& Arnold, M. E. (2003). Why they come, why they go, and why they stay: Factors affecting volunteerism in 4-H programs. Journal of Extension, 41(4). https://www.joe.org/joe/2003august/rb5.php 